\title{
Energy Security and Sustainability in Japan
}

\section{Jeffrey Kucharski ${ }^{a^{*}}$, Hironobu Unesaki ${ }^{\mathrm{b}}$}

\author{
${ }^{a}$ Graduate School of Energy Science, Kyoto University, Yoshida \\ Honmachi, Sakyo-ku, Kyoto, 6o6-8501, Japan \\ ${ }^{b}$ Graduate School of Energy Science, Kyoto University, Yoshida \\ Honmachi, Sakyo-ku, Kyoto, 6o6-8501, Japan
}

Received: December 03, 2016/ Accepted: June 01, 2016

\begin{abstract}
The purpose of this paper is to review Japan's energy security and sustainability (i.e.: climate change) policy targets during the 2000-2013 period, to evaluate whether the country was successful in meeting these targets, and to assess the extent to which it was able to balance energy security and sustainability goals. This paper thus aims to fill a gap in the literature with respect to knowledge about the effectiveness of energy and sustainability policymaking in Japan.
\end{abstract}

Our results show that in the 2000-2010 period, Japan pursued both energy security and climate change policies simultaneously and the country's energy and climate policies reflected an integrated approach, with mixed results. While Japan did make progress in improving its energy security situation and did manage to achieve its Kyoto commitments, the achievement of some policy targets fell short of expectations. Sustainability performance after the Fukushima accident was more negatively impacted than would have been the case had there been a greater share of other (non-nuclear) lowcarbon sources in the electricity generation mix. We also show that in the wake of the Fukushima disaster and the subsequent shutdown of nuclear power capacity, sustainability issues were overshadowed as Japan's priorities turned toward dealing with disaster recovery, energy security and economic issues. Four years after Fukushima, policy trends indicate that a restoration of the balanced approach to energy security and sustainability issues is underway as Japan recommits to global climate change targets, announces new sustainability initiatives and initiates nuclear power plant restarts.

Keywords: Energy security; sustainability; energy policy
Abbreviations:

\begin{tabular}{|lll|}
\hline GHG & $:$ & Green House Gasses \\
GDP & $:$ & Gross Domestic Product \\
UNFCC & $:$ & United Nations Framework Convention on \\
& & Climate Change \\
\hline
\end{tabular}

\section{Introduction}

Energy security and sustainability policies have developed in different research streams and tend to be treated separately even though the two policy areas are intimately related and increasingly co-dependent [1]. The climate change/sustainability literature has tended to ignore energy security issues in low-carbon scenarios [2], and greater attention to the trade-offs and synergies between energy security and climate change mitigation policies has been called for [3]. For policymakers, energy security is often considered a near-term, national issue, whereas climate change is viewed as a global, long-term problem [4]. Given the increasing importance of achieving both sustainability and energy security goals simultaneously over the longterm, integrated approaches that assess the interactions between both concepts are necessary [1]

This study reviews Japan's long-term energy security and sustainability (i.e.: climate change) policy targets and goals. As a country with few non-renewable natural resources, Japan is highly reliant on imports of fossil fuels to power its economy. As a result, energy security issues occupied a prominent place in Japan's policy priorities. Sustainability policy also rose to prominence in the period after Japan acceded to the Kyoto Protocol in December 1997. In order to meet Japan's climate targets within the first commitment period (2008-2012) major changes in Japanese energy policy were implemented in the lead-up to the agreement coming into force.

Despite the obvious linkage between energy security and sustainability policies, there are a limited number of studies in the literature that take an integrated approach to their assessment [4]. Very few studies have examined the effectiveness of Japan's approach to energy security and sustainability over a longer time frame. The purpose of this paper is therefore to review Japanese long-term energy security and sustainability policy targets in the 2000-2013 period and to assess how effective government policies were in achieving these targets, including the extent to which they promoted a balanced and integrated approach to the enhancement of long-term energy security and sustainability. 


\section{Research Method}

Information on Japanese policies and targets were collected from primary sources including published government reports and policy documents. Documents were reviewed to extract information on historical data, including adjustments and revisions that were made during the period under study. Sources included the Ministry of Economy, Trade and Industry (METI), Ministry of Environment (MOE) and the Cabinet Office. Energy statistics and climate related data were collected from primary or secondary sources including from the Japanese government (especially METI and MOE), Institute of Energy Economics Japan (IEEJ), the IEA, UN and other sources. Energy security and sustainability indicators were calculated from IEA, IEEJ [5], and UN data. The Shannon-Weiner Index and Energy Security Index were both calculated to reflect the share of each fuel in Japan's primary energy supply.

\section{Energy security and sustainability policies in Japan}

\subsection{Responsibility for energy and sustainability policies}

As an island nation dependent on exports of manufactured products, energy security has been a dominant theme in Japanese energy policy particularly since the two oil shocks of the 1970's. Japan has almost no domestic sources of fossil fuels or uranium and imports virtually all of its nonrenewable energy resources. Consequently, over the period under study energy was treated as a strategic and important national security issue [6]. In Japan, the role of government is seen as essential to shaping the development of the energy system in order to ensure long-term energy security.

Energy policy in Japan is primarily the responsibility of METI (prior to 2001, the Ministry of International Trade and Industry, MITI). A key tool for METI's energy policy planning was the Long-term Energy Supply and Demand Outlook. The outlooks were prepared by the Advisory Committee for Natural Resources and Energy, a committee whose role is to advise the Ministry of Economy, Trade and Industry. The outlook was meant to provide guidance for policy and plans by setting targets for Japan's energy mix, including energy demand by sector, primary energy supply, electricity generation and $\mathrm{CO}_{2}$ emissions [7]. The outlook is best viewed as a scenario of Japan's energy policy aspirations, rather than as a forecast [8]. Even so, policymakers, industry and other stakeholders used the outlook as a basis for forward planning. Targets for components of primary energy supply were reflected in long-term energy supply and demand outlooks issued in 2001, 2005 and 2008.

Climate and environmental policies are primarily the responsibility of the MOE and are expressed mainly through the Basic Environment Law (enacted in 1993) and the Basic Environment Plan which sets out the measures to be taken by the national and local governments, citizens, businesses and organizations. In Japan, sustainability goals are often included in or linked to energy policies. For example, in developing its "intended nationally determined contribution" (INDC) for global climate change negotiations, Japan links its proposals to national energy policies [9].

\subsection{Balancing the 3-E's}

During the 2000-10 period, the Japanese government itself identified a number of risks threatening its long-term energy security including: instability in the Middle East, resource competition, increasing resource prices, natural disasters, insufficient investment in upstream energy supplies and uncertainties arising from market liberalization [10]. In line with these developments, Japan took a major step toward a more comprehensive approach to energy policy planning with the enactment of the Basic Act on Energy Policy in 2002. The Act stipulated that energy policy development should be based on three fundamental principles known as the "3-E's": energy security, environmental protection and economic efficiency. Based on these principles, the government issues a Strategic Energy Plan at least once every three years [11]. Other energy-related plans published during the period included the New National Energy Strategy (NNES) of 2006 which placed a strong focus on energy security issues and outlined a series of measures the country would take to address perceived threats [12].

Energy security and sustainability policies have had a strong linkage ever since the oil shocks of the 1970's. Energy efficiency and conservation policies implemented since then resulted in a $42 \%$ reduction in energy consumption per unit of GDP between 1973 and 2012 [5]. Sustainability issues rose to prominence in 1997 as the country sought to exert global climate leadership by hosting international climate talks in Kyoto. The resulting Kyoto Protocol was the first international climate change agreement to include binding GHG commitments. Japan ratified the Kyoto Protocol in 2002 and it entered into force in February 2005. Under the Protocol, the country committed to reduce its greenhouse gas emissions by $6 \%$ from 1990 levels. The Kyoto Protocol Target Achievement Plan implemented in 2005 was the guiding plan for Japan to reach its commitments. A number of other policies were implemented to achieve sustainability goals during the period. These included:

A voluntary emissions trading scheme and a domestic offset scheme for small businesses to enhance their efficiency and lower emissions in 2005.

Various measures in the NNES including energy conservation programs such as the Frontrunner Plan and energy efficiency technology development. 
- The Cool Earth 50 policy announced in May 2007 that was aimed at reducing global GHG emissions by $50 \%$ by 2050 .

- The so-called "Fukuda Vision" that included plans for the development of advanced and innovative technologies to significantly reduce greenhouse gases by 2050 .

\section{Analysis of policy objectives and targets}

In order to meet the Kyoto Protocol's targets within the first commitment period (2008-2012) and address growing energy security concerns, the Japanese government set 2010 as a target year to achieve a range of energy security and sustainability policy objectives that were reflected in the outlooks. In the following sections we identify and analyze Japanese government energy and sustainability (climate change) policies and targets that were in place over the 2000-2013 period.

\subsection{Energy policies and targets, 2000-2010}

The Long-term Energy Supply and Demand Outlook of July, 2001 consisted of two scenarios, the base case and the policy case with targets set for 2010. For versions of the outlook spanning 2001 to 2008 , the target scenarios were based on FY 2010 because Japan had committed to goals under the Kyoto Protocol and achieving its emissions targets within the first commitment period (2008-2012) was an important policy goal for Japan. The base case was a "business as usual" case that incorporated all the energy efficiency and environmental measures that had been implemented up to 2001. The policy case targets incorporated the additional policies and measures needed to meet the Kyoto targets as well as meet energy security goals, including a wellbalanced energy supply and electricity mix. The policy case included the following objectives [8]:

- Total final consumption would be reduced below current levels.

- $\quad$ Oil supply would be reduced below current levels through diversification and energy conservation measures.

- Coal use would be reduced through fuel conversion and other measures.

- Natural gas supply would be increased from current levels through fuel conversion and other measures.

- Nuclear power supply would reach $42 \%$ by 2010 by building new plants (the government targeted 10-13 reactors by 2010 in addition to the 52 commercial units that existed in 2002) and improving load factors.
- $\quad$ The supply of new and renewable energy sources would be increased by a factor of three.

In order to assess Japan's performance and evaluate the government's objectives, we compare the policy case targets that the government set with actual primary energy supply figures over the $2000-2010$ period. Table 1 summarizes components of Japan's primary energy supply (PES) targets. Table 2 summarizes the actual amounts. Data have been converted to standardized units (in millions of kiloliters of oil equivalent) for comparability.

Table 1 Long-term Energy Supply and Demand Outlooks: primary energy supply targets for 2010

\begin{tabular}{lccc}
\hline & \multicolumn{3}{c}{ 2010 Targets } \\
\hline M kl of oil equiv. & $\begin{array}{c}(\mathbf{2 0 0 1} \\
\text { Outlook) }\end{array}$ & $\begin{array}{c}(2005 \\
\text { Outlook) }\end{array}$ & $\begin{array}{c}(2008 \\
\text { Outlook) }\end{array}$ \\
\hline Fossil fuels: & 468 & 457 & 462 \\
Oil & 271 & 244 & 232 \\
Coal & 114 & 105 & 117 \\
Natural gas & 83 & 108 & 113 \\
Nuclear & 93 & 85 & 83 \\
Hydro & 20 & 21 & 19 \\
Geothermal & 1 & 1 & 1 \\
New energy & 20 & 21 & 20 \\
Domestic Supply of & & & 584 \\
Primary Energy & $\mathbf{6 0 2}$ & 584 & \\
\hline
\end{tabular}

Table 2 Primary enegy supply: actual amounts, 2000-2013

\begin{tabular}{|c|c|c|c|c|c|}
\hline & & & Chang & & Chang \\
\hline & 2000 & 2010 & e & 2013 & \\
\hline $\begin{array}{l}\text { M kl of oil } \\
\text { equiv. }\end{array}$ & $\begin{array}{c}\text { (actual } \\
\text { ) }\end{array}$ & $\begin{array}{c}\text { (actual } \\
\text { ) }\end{array}$ & $\begin{array}{l}(2010 / \\
2000)\end{array}$ & $\begin{array}{c}\text { (actual } \\
\text { ) }\end{array}$ & $\begin{array}{l}(2013 / \\
2010)\end{array}$ \\
\hline Fossil fuels: & 477.6 & 466.0 & $-2.4 \%$ & 500.0 & $7 \cdot 3 \%$ \\
\hline Oil & 288.1 & 228.0 & $-20.9 \%$ & 233.0 & $2.2 \%$ \\
\hline $\begin{array}{l}\text { Coal } \\
\text { Natural }\end{array}$ & 108.5 & 128.7 & $18.5 \%$ & 135.6 & $5.4 \%$ \\
\hline gas & 80.9 & 109.3 & $35.1 \%$ & 131.4 & $20.2 \%$ \\
\hline Nuclear & 74.2 & 64.4 & $-13.2 \%$ & 2.1 & $-96.8 \%$ \\
\hline Hydro & 20.1 & 18.4 & $-8.5 \%$ & 17.5 & $-4.8 \%$ \\
\hline Geothermal & 0.8 & 0.6 & $-23.3 \%$ & 0.6 & $0.0 \%$ \\
\hline $\begin{array}{l}\text { New energy } \\
\text { Domestic } \\
\text { Supply of } \\
\text { Primary }\end{array}$ & 15.2 & 20.5 & $35 \cdot 4 \%$ & 22.4 & $9 \cdot 3 \%$ \\
\hline $\begin{array}{l}\text { Energy } \\
\text { Total GHG } \\
\text { emissions } \\
\text { (Mt of } \mathrm{CO}_{2} \\
\text { equiv.) }\end{array}$ & 587.8 & 569.9 & $-3.0 \%$ & 542.7 & $-4.8 \%$ \\
\hline
\end{tabular}

\subsubsection{Primary energy supply targets, 2000-2010}

Analysis of the targets and actual PES figures shows that total primary energy supply in 2010 declined about $3 \%$ from 
the level in 2000 and fell more than levels targeted in the outlooks. Also, total final energy consumption fell by $9.7 \%$ compared to 2000 [5]. While it is difficult to attribute direct causes to the reduction in energy demand, energy efficiency and conservation programs and the recession following the global financial crisis in 2008-09 may have been contributing factors [13].

In the 2001 outlook, METI aimed to reduce oil dependency to about $45 \%$ by the year 2010 which would be achieved mainly by increasing the use of nuclear power and modest increases in "new energy". Looking at specific components of PES over the 200o-10 period we note that by 2010, Japan had successfully reduced its reliance on oil by about $21 \%$, more than targeted in 2001 .

The failure to reach nuclear power plant targets (discussed below) by a wide margin only resulted in a $13 \%$ fall in the share of nuclear power in PES because of the unexpectedly large reduction in domestic supply of primary energy. While the government aimed to reduce coal's share by 2010, it's share in PES actually increased significantly during the period. Natural gas also increased its share. Both of these fuels increased to fill the gap left by the reduction in nuclear power generation (see below). Meanwhile, hydro and geothermal remained almost unchanged over the period.

\subsubsection{Electricity mix targets, 2000-2010}

Nuclear power was targeted to play a key role in helping Japan improve its long-term energy security, diversify away from oil and achieve its Kyoto commitments. The government viewed nuclear power as a low-carbon energy source and as an important "quasi-domestic" source of energy given that uranium can easily be stockpiled and the fuel cycle would allow plutonium to be enriched and recycled, thereby improving efficiency and reducing waste material. However, despite the ambitious targets set in the outlooks, Japan had to revised down the number of reactors from 10-13 in the 2001 outlook, to 6 in the 2005 outlook. By 2010, a total of only five reactors had actually come online and the share of nuclear power in the electricity mix actually fell. By 2010 the share of nuclear power was well short of the government's original goals and reflected the loss of public confidence in nuclear power as a result of a series of accidents and scandals [14].

Coal steadily increased its share of the electricity mix, increasing its share significantly over the target. In the 2000-2010 period the coal market in Japan was fully liberalized, coal prices were cheap relative to other fossil

\footnotetext{
1 "New energy" is a term used in Japan and includes the following energy sources: photovoltaic (PV), wind power, solar thermal, waste power, thermal utilization of waste, fuel production from waste, temperature difference energy, natural gas cogeneration and fuel cells.
}

fuel alternatives and utilities made independent investment decisions on power generation technologies. The increase in coal's share can also be attributed to the uncertainty surrounding the extent to which nuclear generation could actually increase in the face of public concerns over nuclear safety. Imports of thermal coal thus increased steadily over the period while gross thermal power generation efficiency also improved with Japan gaining global leadership in clean and efficient coal-fired generation technologies [15]. The increase in LNG over the period can be attributed to several factors, including the need to diversify the fuel mix, lower $\mathrm{CO}_{2}$ emissions, and the need to meet demand peaking requirements [16].

In 1996 and 2001, as part of efforts to promote "zeroemission" electricity generation, the Japanese government set an overall target for new energy (excluding hydro and geothermal) of $3.1 \%$ in total primary energy supply by fiscal 2010. This very modest target was exceeded by a small margin (see Table 3). However, about $89 \%$ of electricity from new energy was produced from biomass and waste materials in 2010, while renewables such as solar PV and wind power had only about $1 \%$ share. Renewables and cogeneration capacity additions fell well short of 2010 targets in all cases (see Table 4).

Table 3 Long-term Energy Supply and Demand Outlooks: percent share in primary energy supply, 2000-2013

\begin{tabular}{|c|c|c|c|c|c|}
\hline & $\begin{array}{c}2000 \\
\text { (actua } \\
\text { 1) }\end{array}$ & $\begin{array}{c}2001 \\
\text { (Outlo } \\
\text { ok) }\end{array}$ & $\begin{array}{c}2010 \\
\left(\begin{array}{c}\text { actua } \\
1)\end{array}\right. \\
\end{array}$ & $\begin{array}{c}2001 \\
\text { Outlo } \\
\text { ok } \\
\text { vs } \\
2010 \\
\text { actual } \\
\end{array}$ & $\begin{array}{c}2013 \\
(\text { actua } \\
1)\end{array}$ \\
\hline Fossil fuels: & $81.2 \%$ & $77.7 \%$ & $81.8 \%$ & $-0.4 \%$ & $92.1 \%$ \\
\hline Oil & $49.0 \%$ & $45.0 \%$ & $40.0 \%$ & $-15.9 \%$ & $42.9 \%$ \\
\hline Coal & $18.5 \%$ & $18.9 \%$ & $22.6 \%$ & $12.9 \%$ & $25.0 \%$ \\
\hline Natural gas & $13.8 \%$ & $13.8 \%$ & $19.2 \%$ & $31.7 \%$ & $24.2 \%$ \\
\hline Nuclear & $12.6 \%$ & $15.4 \%$ & $11.3 \%$ & $-30.7 \%$ & $0.4 \%$ \\
\hline Hydro & $3.4 \%$ & $3 \cdot 3 \%$ & $3.2 \%$ & $-8.1 \%$ & $3.2 \%$ \\
\hline Geothermal & $0.1 \%$ & $0.2 \%$ & $0.1 \%$ & $-40.6 \%$ & $0.1 \%$ \\
\hline New energy & $2.6 \%$ & $3.1 \%$ & $3.6 \%$ & $2.7 \%$ & $4.1 \%$ \\
\hline Domestic & & & & & \\
\hline $\begin{array}{l}\text { Supply } \\
\text { of Primary } \\
\text { Energy }\end{array}$ & $100.0 \%$ & $100.0 \%$ & $100.0 \%$ & $-5 \cdot 3 \%$ & $100.0 \%$ \\
\hline
\end{tabular}

Table 4 Renewables and co-generation targets and actual amounts (MW), 2000-2010

\begin{tabular}{lcccc}
\hline \multicolumn{1}{c}{ Source } & $\mathbf{2 0 0 0}$ & & $\mathbf{2 0 1 0}$ & \\
& Actual & Target & Actual & $\begin{array}{c}\text { Diff. from } \\
\text { Target }\end{array}$ \\
\hline PV & 330 & 4820 & 3620 & $-33 \%$ \\
Wind & 144 & 3000 & 2442 & $-23 \%$ \\
Biomass \& Waste & 1100 & 4500 & 2404 & $-87 \%$ \\
$\begin{array}{l}\text { Natural gas co- } \\
\text { generation }\end{array}$ & 2814 & 4988 & 4043 & $-23 \%$ \\
\hline
\end{tabular}




\subsection{Policies and targets, 2011-2013}

In the Strategic Energy Plan of 2010, the government reaffirmed that nuclear power would play a major role in helping meet Japan's climate change targets. In addition to a new target of 9 additional nuclear power plants to be completed by 2020 , and 14 by 2030 , the plan called for raising the "zero-emission power source ratio" to about 70\% (from 38\% in 2010) and cutting $\mathrm{CO}_{2}$ emissions in the residential sector by $50 \%$ [17].

In the wake of the Fukushima disaster, Japan's nuclear reactors were progressively shut down for safety inspections by the newly established Nuclear Regulation Authority (NRA). By the end of 2013 nuclear power's share of PES had dropped by almost $97 \%$. As a result, Japan's power generation mix became heavily concentrated, with the share of fossil fuels (especially coal and LNG) in PES increasing from about $81 \%$ in 2010 to more than $92 \%$ in 2013.

\subsection{Sustainability policies and targets}

At preliminary UN climate talks in Bangkok in 2009, Japan announced it would target a $25 \%$ reduction in GHG's over 1990 levels - the most ambitious target proposed by any major developed nation at the conference [18]. Japan reaffirmed this target at the UNFCC Copenhagen conference in 2009. It premised this commitment on an agreement with ambitious targets and where all major economies participate. However, at climate talks in Cancun in 2010, Japan (and three other countries) refused to agree to an extension of the Kyoto Protocol on the grounds that it did not include major emitters such as the U.S. and China.

After the March 2011 disaster, and in a major departure from its previous commitment, Japan proposed to reduce its carbon emissions by $3.8 \%$ by 2020 compared to 2005 levels at climate talks in Warsaw in November 2013 [19]. Since emissions in the country grew about 7\% between 1990 and 2005, this actually represented a 3.1\% increase over 1990 levels. Japan was widely criticized for taking this position. The reasons it gave for lowering the level of ambition were attributed to the impact of the indefinite shutdown of all of the country's nuclear reactors and the "zero-base review" of earlier policies that followed the 2011 disaster [19]. After Fukushima, old oil-fired thermal power plants had been brought back online and new gas-fired plants were built to make up for the loss of electricity generation. As a result, by the end of 2013 Japan's GHG emissions had risen to 1,395 Mt $\mathrm{CO}_{2}$, an increase of $8.5 \%$ over 2010 levels, with all of the increase coming from the power sector (see Table 2). This was the highest level since comparable data became available in fiscal 1990.

Subsequently, in July 2015 as momentum started to rebuild toward forging a substantive agreement at COP 21 in Paris, Japan announced that it would reduce its GHG emissions by $26 \%$ over 2013 levels by 2030 [20]. This proposal was made in consideration of the government's plan for the electricity generation mix, which was released in April, 2015. Japan's electricity sector is substantially liberalized but through its regulatory authority, the government still exerts significant influence over system adequacy and long-term planning. Thus, nuclear generation was targeted to reach $20-22 \%$ of the mix while renewables were targeted to make up $22-24 \%$. In total, the government expected "zero-emissions" generation to account for up to $44 \%$ of the generation mix by 2030. On the heels of this announcement, Japan's Federation of Electric Power Companies also made a voluntary commitment to reduce $\mathrm{CO}_{2}$ emissions by $35 \%$ per $\mathrm{kWh}$ by $2030[21]$.

\section{Discussion}

In order to more fully assess Japan's policy outcomes, we computed several indicators to measure trends in energy security and sustainability over the 2000-13 period. Since import dependence for fossil fuels exceeded $95 \%$ over the whole period, Japan is highly vulnerable to disruptions in energy supplies. The country faces a wide variety of potential threats and uncertainties to its energy security over which it has little influence. In his seminal work on diversity, Stirling [22] showed that diversification is the best method of building resilience in energy systems that are exposed to incertitude.

In order to measure the trend in energy security in Japan, we apply two well-established indices of diversity. The first is the Shannon-Weiner index (SWI) which has been shown to appropriately reflect both variety and balance in the portfolio of fuel types in primary energy supply [22]. In this paper, SWI measures diversity in five primary fuels: crude oil, coal, natural gas, nuclear and renewables. The range of values for the indicator are between $\mathrm{o}$, which represents $100 \%$ reliance on a single fuel, and 1.67 which represents a primary energy mix which is fully diversified and balanced among the five main fuel types. Therefore, the higher the index value the more diversified the fuel mix is. The results (see Table 5) show that, in absolute terms, Japan's diversity of primary energy supply up to 2010 was very good at a level averaging about 1.4. However, the trend after the Fukushima disaster in 2011 was sharply lower.

Japan also faces potential threats from disruptions to fuel imports from supplier countries, including from political turmoil, wars, piracy, sea lane blockages and the exercise of market power. The Hirfendhal-Hirschman Index (HHI) has been used in several studies to measure the diversity of energy supplier countries and to assist in assessing the market power of suppliers [23]. Values for the index range from o where there is perfect competition with innumerable suppliers, to 10,000 where the market is supplied exclusively by a single supplier. The results are found in Table 5 .

Given that these two extreme values for the HHI are highly unlikely in the real world, we can judge that Japan's index values for crude oil and natural gas are moderately 
low, indicating a relatively high degree of diversification. The trends for these two fuels over time have been relatively flat, with diversification for natural gas improving slightly over time. With regard to coal, the index is judged to be moderately high, reflecting an increasing level of concentration. In particular, imports of coal from Australia increased by $41 \%$ between 2000 and 2013 and Australia's share of Japan's coal imports rose from $60 \%$ in 2000 to $64 \%$ in 2013 [24].

We can also examine Japan's energy security performance relative to China and S. Korea, two Asian countries which are also highly reliant on fossil fuel imports. The trend in primary energy supply diversification (SWI) in Figure 1 shows that Japan maintained a relatively higher level of diversification over the entire period than the other two countries.

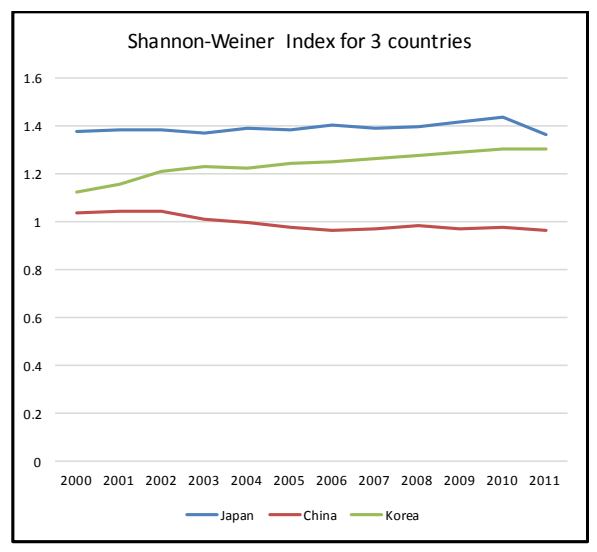

Figure 1 SWI for 3 countries

With respect to sustainability, we calculated two indicators: carbon intensity which is a measure of carbon use in the economy, and carbon emissions per capita which is a measure of carbon use in society as a whole. The results (see Table 5) show that both carbon intensity and carbon emissions per capita declined steadily up to 2011. While intensity increased slightly after 2011, per capita emissions increased significantly. The changes after 2011 were due largely to the increased reliance on fossil fuels in the power sector, which were required to replace nuclear power.

Table 5 Energy security and sustainability indicators
Our analysis demonstrates that even though not all the outcomes underlying the policy case in the 2001 outlook (see section 4.1) were achieved, Japan managed to maintain a relatively high level of energy security over the 2000-2010 period. It did this primarily by reducing dependence on oil and increasing the share of nuclear power in Japan's primary energy supply. Total final energy consumption in 2010 was $3 \%$ lower than in 2000 [5]. By 2010, the diversity of fuel sources in Japan's electricity generation mix was better than in 2000 (see Tables 5 and 6). The modest targets set for new energy (including renewables) were met and slightly exceeded.

Table 6 Electricity mix targets and actual amounts for 2010

\begin{tabular}{lcccc}
\hline Source & $\begin{array}{c}\mathbf{2 0 0 0} \\
\text { Actual }\end{array}$ & $\begin{array}{c}\mathbf{2 0 0 1} \\
\text { Outlook }\end{array}$ & $\begin{array}{c}\mathbf{2 0 0 5} \\
\text { Outlook }\end{array}$ & $\begin{array}{c}\mathbf{2 0 1 0} \\
\text { Actual }\end{array}$ \\
\hline Thermal & $56 \%$ & $47 \%$ & $49 \%$ & $60 \%$ \\
Coal & $18 \%$ & $16 \%$ & $17 \%$ & $23 \%$ \\
LNG & $26 \%$ & $26 \%$ & $25 \%$ & $31 \%$ \\
Oil & $11 \%$ & $5 \%$ & $7 \%$ & $5 \%$ \\
Nuclear & $34 \%$ & $42 \%$ & $39 \%$ & $31 \%$ \\
Hydro & $10 \%$ & $10 \%$ & $11 \%$ & $8 \%$ \\
Geothermal & $0.4 \%$ & $0.4 \%$ & $0.4 \%$ & $0.3 \%$ \\
New Energy & $0 \%$ & $1 \%$ & $1 \%$ & $1 \%$ \\
Total & $100 \%$ & $100 \%$ & $100 \%$ & $100 \%$ \\
\hline
\end{tabular}

Despite these achievements, the share of fossil fuels in PES remained unchanged over the period ending at $81 \%-$ the same as it was in 2000. Ambitious targets for expanding nuclear power were never reached despite the targets being revised down multiple times. Renewables and co-generation capacity additions also fell well short of the targets. As a result, the share of fossil fuels in the electricity generation mix increased to $60 \%$ by 2010. Coal and natural gas generation increased to help cover the steady growth of peak load over much of the 2000-2013 period and also helped increase reserve margins. Given various physical and regulatory constraints, hydro and geothermal power were unable to grow during the period.

Due to various factors including energy efficiency and conservation measures and falling energy demand, Japan managed to reduce its total $\mathrm{CO}_{2}$ emissions and emissions intensity over the 2000-2010 period. However, the inability

\begin{tabular}{|c|c|c|c|c|c|c|c|c|c|c|c|c|c|c|}
\hline & 200 & 2001 & 200 & 2003 & 200 & 200 & 200 & 200 & 200 & 200 & 2010 & 2011 & 2012 & 201 \\
\hline & o & & 2 & & 4 & 5 & 6 & 7 & 8 & 9 & & & & 3 \\
\hline \multicolumn{14}{|l|}{$\begin{array}{l}\text { Hirfendhal-Hirschman Index } \\
\text { (HHI): }\end{array}$} & 448 \\
\hline HHI for coal & o & 1668 & 1640 & 1670 & 1747 & 1899 & 9 & 1804 & 1803 & 8 & o & 9 & 1820 & 6 \\
\hline HHI for crude oil & 1614 & 1888 & 1944 & 1852 & 1790 & 1781 & 1977 & 1484 & 1399 & 1881 & 1737 & 1900 & 1224 & 182 \\
\hline HHI for nat gas & 203 & & & & & & 1608 & & & 1464 & 1427 & 1281 & & 8 \\
\hline & 2 & & & & & & & & & & & & & 1317 \\
\hline Shannon-Weiner Index (SWI) & 1.37 & 1.38 & 1.38 & 1.37 & 1.39 & 1.38 & 1.40 & 1.39 & 1.40 & 1.42 & 1.44 & 1.36 & 1.24 & 1.23 \\
\hline $\begin{array}{l}\text { Carbon intensity }\left(\mathrm{kgCO}_{2} / 2005\right. \\
\text { \$US PPP) }\end{array}$ & 0.32 & 0.31 & 0.32 & 0.32 & 0.31 & 0.31 & 0.30 & 0.30 & 0.28 & 0.28 & 0.28 & 0.30 & 0.30 & $\begin{array}{l}0.3 \\
0\end{array}$ \\
\hline $\mathrm{CO}_{2}$ emissions per capita ( $\mathrm{tCO}_{2}$ ) & 9.12 & 9.00 & 9.26 & $9 \cdot 30$ & $9 \cdot 31$ & $9 \cdot 36$ & 9.25 & $9 \cdot 54$ & 8.88 & 8.41 & 8.79 & 9.21 & $9 \cdot 54$ & $\begin{array}{l}9 \cdot 7 \\
0\end{array}$ \\
\hline
\end{tabular}


to meet nuclear targets and the weak policy support for renewables expansion made the challenge to reach the Kyoto targets that much more difficult since the growth of other low-emission sources including hydro, geothermal and new energies were relatively insignificant. As a result, while GHG emissions were lower in 2010 that in 2000 , they were still higher than in 1990. However, under the Kyoto Protocol Target Achievement Plan the objective to meet the $6 \%$ target was to be met by reducing domestic GHG emissions by $0.6 \%$ annually compared to base year (1990) combined with $3.8 \%$ from a forest sink and $1.6 \%$ by employing other Kyoto mechanisms ${ }^{2}$. Due to slow GDP growth and the use of the Kyoto mechanisms, Japan was able to meet its Kyoto Protocol commitments [23].

In the wake of the Fukushima Daiichi nuclear power plant accident in March 2011, the attention of policymakers turned to investigating the causes of the accident and putting in place regulatory and policy reforms to enhance the safety and security of nuclear facilities. Given the magnitude and consequences of the disaster and the importance in addressing an extremely wide range of issues from disaster relief to regulatory reform, the attention and resources of the government shifted to dealing with the most urgent issues for much of this period. One of the major consequences of the disaster was the rapid increase in GHG emissions associated with the increase in fossil fuel power generation, which served to compromise Japan's climate mitigation efforts.

It is not surprising that given the circumstances, the Japanese government sought to avoid major new climate change commitments while it assessed the impact of the disaster on the future of the energy system. Energy security concerns took precedence as rising energy costs led energyintensive industries to close down or move offshore while capital investments were postponed [25]. In particular, uncertainty surrounding the restart of nuclear power plants and public concerns over nuclear power complicated energy policymaking and led to a four-year period lasting from March of 2011 to April of 2015 in which the government provided no firm guidance or targets for the electricity generation sector. Without a signal as to whether and how much nuclear power would be allowed to restart, decisions on constructing nuclear power plants were delayed and new fossil-fuel based thermal generation expanded to fill the gap in generation capacity, with negative consequences for Japan's balance of payments. As a result, efforts to balance the 3-E's + S ("S" for safety was added after the Fukushima disaster) were compromised as the country found itself having to prioritize energy security and economic efficiency

\footnotetext{
${ }^{2}$ Kyoto mechanisms were designed to give flexibility to countries in meeting their emissions targets such as through projects that reduce emissions, utilizing "sinks" (eg: forests) or engaging in emissions trading with other countries.
}

over sustainability in order to protect the economy and continue to provide essential services to its citizens.

While Japan was widely criticized by environmental advocates for lowering its level of ambition in the Warsaw proposal and in its recent COP 21 proposal, its stance is understandable in light of the realities of the postFukushima situation with a reduced reliance on nuclear power, a need to limit energy price increases that would further reduce Japan's competitiveness, and an ongoing concern with energy security issues. With the reduced role planned for nuclear power, the government appears to believe that Japan's ability to achieve deeper reductions in GHG emissions beyond what has already been proposed is limited in the short-term, especially given the continued commitment to balancing the 3-E's. Given Japan's already impressive improvements in energy efficiency, there appears be is little room to achieve further dramatic cuts. In 2012, Japan's carbon intensity performance remained among the best in the developed world at $220 \mathrm{t} / \$ \mathrm{US}$ million, $18 \%$ less than the OECD average [5].

By 2013 the most urgent post-disaster recovery measures had been taken, regulatory changes for nuclear power had been implemented and a number of government sponsored study groups and committees had reported on recommendations for changes to Japan's energy policies. The most significant and long-awaited announcement concerned the targets for Japan's electricity mix, which were finally announced in April, 2015. The targets reflected a reduced role for nuclear power compared to the preFukushima period but an increase over some low-nuclear scenarios that had been debated soon after the disaster (see: [26]). At the same time, the desire to restrain increases in energy costs that would reduce Japan's export competitiveness combined with efforts to maintain a welldiversified energy mix in order to improve energy security meant that the government saw an important ongoing role for fossil fuel-fired generation (including coal and LNG), as reflected in the electricity mix targets. While renewables have received a strong policy boost from the feed-in tariff scheme of 2012 and capacity additions for solar PV have been dramatic, constraints including the lack of grid connections, limited load sharing among Japan's regions and grid stability concerns associated with intermittency remain issues to be addressed over the longer-term.

Soon after the electricity mix targets were released, the new climate change targets were also announced that proposed more significant emissions reductions than previous proposals (see section 4.3). The government's climate change policy objectives are also being supplemented through the increased use of the UNFCC's Clean Development Mechanisms (CDM). This includes introducing clean energy technologies (such as clean coal technologies and high efficiency gas turbines) in foreign countries and gaining offset credits for GHG reductions achieved. This strategy serves to meet the government's goals of both stimulating energy technology development in Japan as well as expanding Japan's exports. In addition, Japan has committed U.S.\$1.5 billion to the UNFCC's Green 
Climate Fund which will fund programs to reduce overall emissions and enhance climate change adaptation in developing countries [27]. Taken together, these developments suggest that sustainability issues have regained a prominence in energy policymaking that had been lost after Fukushima.

Given the increasing urgency in dealing with the effects of global climate change, the quickest and most cost-efficient method of reducing GHG emissions from power generation in Japan seems to be to safely utilize the country's existing capacity of nuclear power. This would allow Japan to reduce reliance on thermal generation from fossil fuels, lower related price risks (i.e.: reduced exposure to fossil fuel price changes) and improve its sustainability performance significantly in the short-medium term while renewables capacity is scaled up and grid stabilization and integration issues are addressed over the longer-term. Considering the significant investments that have already been made in nuclear technology in Japan, the fact that it is a lowemissions "quasi-domestic" power source and is cost competitive, a strong argument remains for its continued use as long as outstanding safety issues and local concerns are addressed. Japan is faced with energy security challenges that are unlike those of virtually any other developed economy.

\section{Conclusion}

This study analyzed Japan's attempts to achieve both energy security and sustainability goals in the $2000-2013$ period and examined the relationship between energy security and sustainability policies both pre and post-Fukushima. Energy security and climate change policies and targets from the 2000-2010 period indicate that Japan attempted to balance the 3-E's of economic, energy and environmental goals and aimed to achieve both energy security and climate change objectives simultaneously.

Over the 2000-2010 period, Japan's energy security situation generally improved and a number of energy security and sustainability targets were achieved. However, other targets and objectives were not met. The reasons for missed targets would require analysis beyond the scope of this paper but may reasonably be attributed to a number of factors including overly ambitious goals, growing public opposition to nuclear power, changes in imported fuel prices, lack of adequate policy supports, the structural characteristics of electricity markets and other institutional factors.

Energy policy reconsiderations after Great East Japan Earthquake and Tsunami of March 2011 greatly disrupted the balance between the 3-E's as the country's priorities turned to dealing with the effects of the disaster and the severe challenges to its energy security and international competitiveness. The shutdown of all of Japan's nuclear reactors left Japan in a more vulnerable position with respect to long-term energy security and sustainability. The Fukushima disaster and its consequences dealt a huge setback to meeting both energy security and sustainability policy goals as set in the 2010 Strategic Energy Plan.

By the first half of 2015, it appeared that initiatives to improve sustainability were regaining some prominence in Japan's overall energy policy approach. Renewables generation capacity was showing strong increases as a result of the feed-in tariff program, new electricity mix targets were announced that would increase low-emissions generation by 2030, and Japan made enhanced commitments to global climate mitigation efforts. Given the urgency in addressing the energy security and sustainability issues facing Japan, even stronger policy enhancements may be necessary, including moving forward with meaningful structural and institutional reforms within the energy sector. In any case, the developments to date can be viewed as signalling the start of a new phase in the evolution of Japan's energy system post-Fukushima, and a return to a more balanced approach to energy security and sustainability policy in Japan.

\section{References}

[1] A. Checchi, A. Behrens, and C. Egenhofer, Long-term energy security risks for Europe: a sector-specific approach, vol. 309. CEPS, 2009.

[2] M. Nilsson, "Energy security should have more weight in low carbon scenarios,” The Stockholm Environment Institute (SEI), 2014 .

[3] H. Turton and L. Barreto, "Long-term security of energy supply and climate change," Energy Policy, vol. 34, no. 15, pp. 22322250, Oct. 2006

[4] D. L. McCollum, V. Krey, and K. Riahi, "An integrated approach to energy sustainability," Nat. Clim. Change, vol. 1, no. 9, pp. 428-429, Dec. 2011.

[5] The Energy Conservation Center, Japan, EDMC Handbook of Energy $\mathcal{E}$ Economic Statistics, 2015th ed. The Institute of Energy Economics Japan, 2015.

[6] D. V. Vivoda, Energy Security in Japan: Challenges After Fukushima. Ashgate Publishing, Ltd., 2014.

[7] K. Fujime, "An Overview of the New 'Long-term Outlook for Energy Supply and Demand' and Its Challenges for the Future," IEEJ, 2004.

[8] IEA, "Energy Policies of IEA Countries: Japan 2003 Review," 2003.

[9] Ministry of Environment, Japan, "Japan's Progress in Developing its Intended Nationally Determined Contribution," 2015. [Online]. Available: https://www.env.go.jp/en/earth/cc/jpdindc.html. [Accessed: o7-Sep-2015].

[10] METI, "Interim report of the Energy Security Study Group," Agency for Natural Resources and Energy, Japan, 2006.

[11] Government of Japan, Basic Act on Energy Policy of 2002 Japan. .

[12] METI, "New National Energy Strategy," Agency for Natural Resources and Energy, Japan, 2006.

[13] M. Sommer, "Why Has Japan Been Hit So Hard by the Global Recession?," International Monetary Fund (IMF), 2009.

[14] World Nuclear Association, "Nuclear Power in Japan | Japanese Nuclear Energy," 2015. [Online]. Available: http://www.worldnuclear.org/info/Country-Profiles/Countries-G-N/Japan/. [Accessed: 20-Jul-2015]. 
[15] NEDO, “Clean Coal Technologies in Japan,” New Energy and Industrial Technology Development Organization (NEDO), 2006.

[16] T. Toichi, "LNG development at the turning point and policy issues for Japan,” Energy Policy, vol. 22, no. 5, pp. 371-377, May 1994.

[17] METI, "Strategic Energy Plan of Japan (2010)," Ministry of Economy, Trade and Industry of Japan (METI), 2010.

[18] BBC News, "Japan vows big climate change cut," $B B C$, o7-Sep2009.

[19] Ministry of Environment, Japan, "Warsaw Climate Change Conference, November 2013 [MOE]," 2013. [Online]. Available: https://www.env.go.jp/en/earth/cc/cop19_summary.html. [Accessed: 04-Sep-2015].

[20]Cabinet Office (Kantei) of Japan, "Global Warming Prevention Headquarters (The Prime Minister in Action) | Prime Minister of Japan and His Cabinet," o2-Jun-2015. [Online]. Available: http://japan.kantei.go.jp/97_abe/actions/201506/2article1.html. [Accessed: o6-Sep-2015].

[21] FEPC, "Establishment of an Action Plan for the Electricity Business for Achieving a Low-Carbon Society," Federation of Electric Power Companies of Japan, 2015.

[22] A. Stirling, "On the economics and analysis of diversity," Sci. Policy Res. Unit SPRU Electron. Work. Pap. Ser. Pap., vol. 28, pp. 1-156, 1998.

[23] IEA/OECD, "Energy Security and Climate Policy: Assessing Interactions," International Energy Agency (IEA), 2007.

[24] United Nations, "UN Comtrade | International Trade Statistics Database," 2015. [Online]. Available: http://comtrade.un.org/. [Accessed: 26-May-2016].

[25] World Nuclear News, "Business calls for stable power supply in Japan," 2013. [Online]. Available: http://www.world-nuclearnews.org/NP-Business-calls-for-stable-power-supply-in-Japan0212131.html. [Accessed: 04-Sep-2015].

[26] The Energy and Environment Council (Japan), "Options for Energy and the Environment." Government of Japan, 2012.

[27] UNFCC, "G20 Back Climate Action as Japan Pledges \$1.5 Billion,” UNFCCC, 16-Nov-2014. [Online]. Available: http://newsroom.unfccc.int/unfccc-newsroom/now-japanpledges-15-billion-to-green-climate-fund/. [Accessed: 19-Sep2015]. 